\title{
FORMULATING AND CONDUCTING INTERNATIONAL STRATEGIES IN EGYPTIAN SMES IN AN UNSTABLE ECONOMIC AND POLITICAL SITUATION
}

\author{
Hanan Gouda \\ Asst. Prof., Arab Academy for Science, Technology and Maritime Transport, College of \\ Management and Technology, EGYPT, hanan.gouda@aast.edu
}

\begin{abstract}
International joint venture (IJV) longevity and stability are frequently used as indicators of collaborative success. The SMEs with wide target to the global market can pursue different international strategic approaches to the targeted markets. The international strategies distinguish three types of globally oriented strategies: the global, the multinational and the multifocal strategies while instability factors influence the organizational behaviours and could have a negative impact on the conducting of the international strategy and the achievement of its goals.

Based on this fact, formulating and conducting an international strategy in an unstable economic and political situation requires either the good knowledge of international competitive rules in an industry and its segments with a high consideration and comprehension of the economic and political situation, or an adapted globalization model capable to face the common challenges of instability.

This paper synthesizes the theoretical and methodological rationales for this approach, taking example of some of the Egyptian SMEs with implications for theory development. A corporate strategy perspective on IJVs is provided, which proposes that the effects of IJV dynamics are meaningfully considered at the parent firm level, and the impact of IJV longevity versus instability depends upon factors such as: the firm's collaborative objectives, post exchange conditions, identification of the strategic issues in different categories of countries, the type of actions to take and the integration and coordination of activities and the IJV's specific governance trajectory. The analysis aids in interpreting prior research and points to the value of more integrative, contingency perspectives on the strategy of globalization and their evolution.
\end{abstract}

Keywords: International strategy, SMEs, joint venture, instability, organizational behavior, globalization models, success.

\section{INTRODUCTION}

The internationalization process of firms has been one of the most researched topics over the past few years. SMEs and firms in most countries play a major role in the economic growth. Currently, SMEs have a disadvantage in resource access for internationalization. 
The elements composing the international development strategy are interdependent. The strategist must ensure their consistency or risk seeing the company's scarce resources dilute. Such a dilution will weaken its positions in the key countries. The international strategy aims then to focus the resources on the activities/countries by using appropriate presence modes to the challenges of the international competition.

Based on this fact, formulating an international strategy in Egypt in this phase requires first a good knowledge of international competitive rules in an industry and its segments with a high consideration and comprehension of the economic and political situation in Egypt.

The formulation of an international strategy essentially involves some questions. First, selecting the countries in which the company will seek to enhance its competitive advantages to obtain sustainable and defendable positions that are likely to generate satisfying returns on investment, greater than the cost of capital while considering the specific risk in each country. They must define according to which criteria the targeted countries will be chosen, what will be the commitment degree of the company in the internationalization and what number of countries in which the company will seek competition.

The conducting of the international strategy requires choosing a strategic approach for the targeted countries. Is the same value proposition going to be offered while seeking the exploitation and development of the same type of competitive advantages everywhere, or, in contrast, new specific advantage combinations will be developed for each country?

Another type of decision concerns the structuring and localization of chain value activities. Should some of the chain links be duplicated to create a dispersed configuration or, on the contrary, is it better to focus maximum links in limited territories? In which measures should the geographically dispersed activities be integrated and coordinated? Should the operational and strategic disconnection of the units localized in different implementation areas be more favored in contrast?

The last interrogation concerns the entry mode of privilege for the targeted countries. Should the internal growth by systematic transfer of knowledge or the adaptation of value proposition be privileged, or, in contrary, the company must focus on the external growth or on the alliances and partnerships with the foreign companies? Should a unique entry mode be systematically used, or, is it better to use all the possible pallets in terms of characteristics or offered opportunities in different countries?

There is a vast literature review for international strategies on large firms (Driouchi and Bennett, 2011; Nielsen and Nielsen, 2011) but very few studies have been tailored to SMEs (Dimitratos and al., 2011; Musso and Francioni, 2013).

The decisions related to international market selection and entry mode selection is considered to be the most critical for a firm's success abroad.

A firm's decision to go abroad is concerned not only with what markets to enter but also with how to enter them (Lee and Lieberman, 2010).

Prior studies have investigated the entry mode choice and motives for SMEs' internationalization (Holmund and Kock, 1998; O'Farrell and Wood, 1998). O'Farrell and Wood (1998) suggest that firms use a variety of entry modes including direct exporting or establish an overseas base through Foreign Direct Investment involving IJVs. Each mode is associated with risk, control, ownership and costs that need to be considered by the owners/managers of SMEs before making decisions. Regarding the theories explaining the entry mode choice, Canabal and White (2008) suggest that, a single theory may not be sufficient to fully explain the reasons behind the choice of the foreign entry mode.

Since the pioneering research of Johanson and Vahlne's (1977) notions on the internationalization process of small firms (Wolff and Pett, 2000), many follow-up studies have addressed how SMEs pursue internationalization, and these related studies for SMEs usually tend to explore their international-involving behavior (e.g. managerial characteristics, motivation for internationalization), the choice of the entry mode strategy, and the internationalization process (Coviello and McAuley, 1999; McDougall and Oviatt, 1997; Oviatt and McDougall, 1997; Barringer and Greening,1998; Wolff and Pett, 2000). However, these previous studies are mostly inherent in focusing on a single theory, and they always give inadequate evidences for SMEs' choice of international entry mode strategy between different economic regions.

In this research, we adapted an exploratory study. There are few studies to refer to because the question is quite recent, facts are known but there is a need for developing a viable theoretical framework. We castoff a qualitative approach adapted to some SMEs working internationally in the field of plastics exportation. We interviewed the owners, collected data and analyzed the factors influencing the conducting of their international strategy. 


\section{DIFFERENT APPROACHES IN THE INTERNATIONAL DEVELOPMENT OF THE COMPANY}

A first typology of international strategies could be elaborated from the extent of the targeted countries and the type of competitive advantage sought in them. It is possible to distinguish between the companies that have a large strategic global field and the companies that have a geographic focused and selective field. The companies with wide target to the global market pursue different strategic approaches to the targeted markets.

Many typologies have been done in the strategic management literature by using other elements concerning the possible choices of international strategies. For example, M.Porter uses the relative choices to the two dimensions of structuring and international configuration of chain value activities (Fig. 1).

He opposes then the multi-domestic strategies which are characterized by a strong geographic dispersion of activities and a weak level of integration to the global strategies that are divided themselves into three categories.

C. Bartlett, S. Ghoshal, N. Nohria, C.K Prahalad, and Y. Doz used the strategic approach dimensions type and also the degree of geographic integration of activities (Fig. 2) to derive typologies.

I. Geographic Configuration of Activities

- High

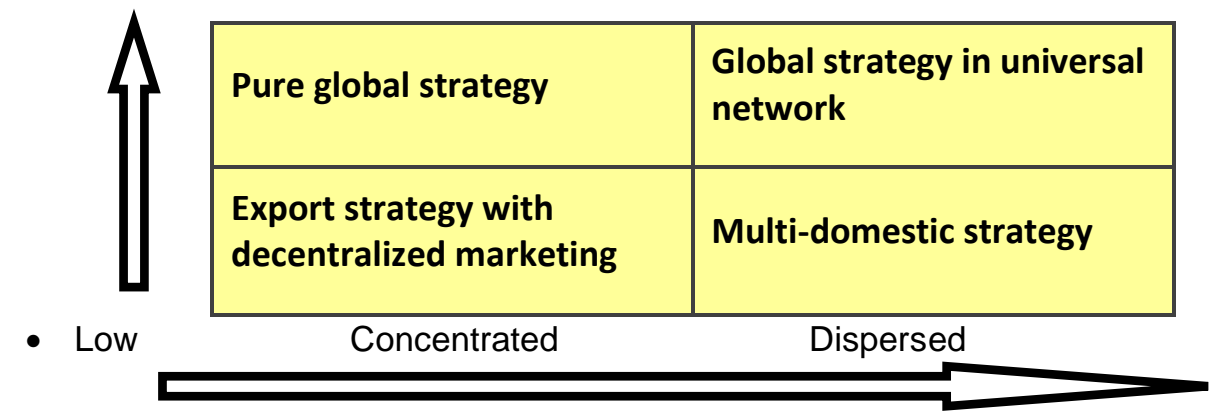

Fig. 1: Typology of international strategies. Source: Adapted from Michael Porter (1986) on the degree of coordination and global integration

II. Degree of Adaptation to the Local Conditions

- High

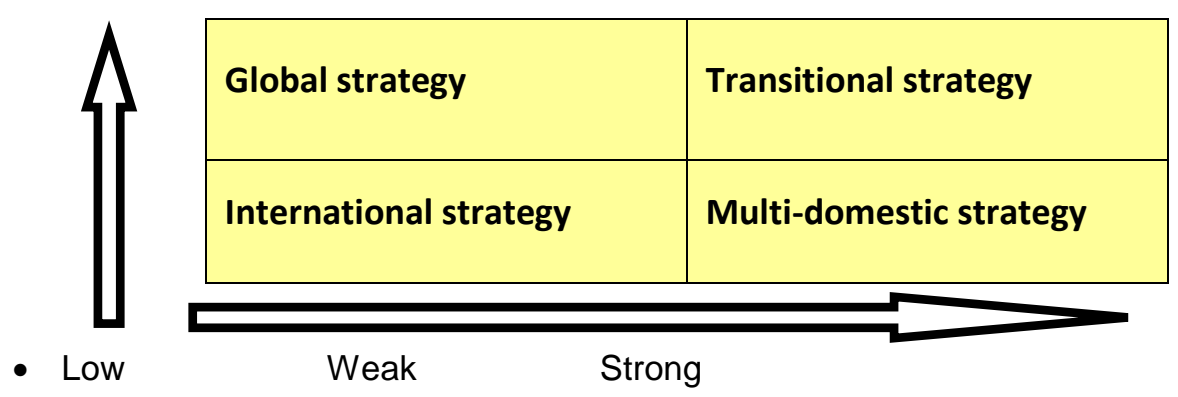

Fig. 2: Typology of international strategies according to the overall grid integration. Source: Adapted from S. Ghoshal and N. Nohria (1993) on the degree of global integration or coordination

The first typologies distinguish four types of strategies (Fig. 1): global, multinational (or multi-domestic), transitional and international. Our concern is the international strategies. The international strategies distinguish three types of globally oriented strategies: the global, the multinational and the multifocal strategies.

There are three types of strategies that are globally oriented: global, multinational, and mixed (combined from different ways of global and multi-domestic strategies). These three types of strategies allow the comparison with four series: the country's choice, the configuration of the chain value's choice, the type of competitive advantage sought, and the choice of the entrance modes.

\section{THE GLOBAL STRATEGY}

The country choice is usually in the first ten to twenty global markets and the emerging countries with a strong 
growth that are privileged targets. The objective is to be present in a significant way in the biggest number of these countries. The pace of the conquest is much sustained.

The configuration of the chain value is mainly focused geographically and aims to globally integrate the activities among the chain value. Also, a respectful importance is given to the relative dispersion of activities downstream of the chain value with a strong global coordination (brand, products, politics, and price).

The type of competitive advantage sought is the identical or similar value proposition on the key markets. It's also about seeking efficiency and advantages of the costs by the integration of activities and the access to the production factors and the resources that optimize the productivity/cost of the used factors.

The chosen entry modes are those which allow having strict control over the operations and strategic decisions. Most of the time, the internal growth is preferred.

\section{THE MULTINATIONAL STRATEGY}

In this type, they depend on the economic attractions of countries and their permeability on distinctive competencies developed in the domestic or basic country. The pace of the markets' conquest is generally progressive. There is a high dispersion of chain value activities with some focused links (finance, research and development, and sometimes the purchase of raw materials). The activities integration is very poor.

Their competitive advantage lies in their differentiated value proposition in most of the targeted countries. At the same time, they put into consideration the main success key factors specifically related to the countries.

The entry mode of multinational strategies is generally varied; according to the characteristics of the countries, the internal growth, the external growth, joint ventures, and license contracts of expertise used.

The multinational strategies consist on selectively investing in a limited number of countries then progressively expanding the geographic field while developing competitive advantages related to the new targeted countries. Then, it's about essentially forming a country portfolio without trying to integrate the assets and operations located in different host countries. The company leads the competition separately, country by country and refers to the competitors and to the local buyers' preferences in the elaboration of the competitive advantage.

\section{THE MIXED STRATEGIES}

In this type, they target the most important zones or privileged regions. In many cases, countries are assembled according to their strategic perceived issues.

For the configuration of the chain value, the activities are generally dispersed for certain links having an important weight in the added costs, geographic focusing efforts are made. The activities coordination is strong. Generally, the competitive advantages are varied; adapting to a market specialty and seeking global efficiency go hand in hand. In other cases, global efficiency is sought at the scale of an area.

Their entrance modes vary according to zones; in case of searching for a network organization, alliances that don't allow a high level of control on the dispersed units are avoided.

The mixed strategies essentially concern the expansion modes focused on the logic of geographic zones. The company leads competition separately zone by zone but only integrates its activities at the heart of each zone.

In this research, we will develop approaches of formulating and conducting global strategies in Small and Medium Enterprises in Egypt nowadays, while putting into consideration the different market changes and the actual situation of the country. It is important to note that most of the SMEs' responses under economic and political instability conditions are usually including -more or less- one of three approaches concerning their international strategies:

- Denial / do nothing / organizational paralysis

- Adaptation / minor adjustment / efficiency gains/ exploitation, but within the existing business model

- Fundamental re-think / radical change/ exploration (where firms view a crisis as an opportunity or necessity to fundamentally review their business model).

The coherence in the choices of elements that shape the international strategies leads to typical configurations. Firstly, we will describe the different types of international strategies. Secondly, we will elaborate the formulation of global strategies, which is the striking phenomenon that is misunderstood since the start of the second millennium in Egypt. 


\section{FORMULATION OF GLOBAL STRATEGIES}

Usually the companies that pursue global strategies take the global market as a unified space and consider that the competitive advantage comes from the global size effect and the global integration of assets and resources. G. Yip describes then the pure global strategy:

- Market: a presence with a meaningful market share in the main markets

- Product offer: standardizing of products or services on the global scale

- Chain value: either focused in one country or focused in many key countries. Also, the activity links are localized in different countries but are perfectly coordinated from the center

- Marketing: the marketing mix is virtually uniform in the main countries

- Strategic moves: they are leaded in a focused way between the main countries while providing interdependence.

\section{DISCUSSION}

As the methodology used in this research was a qualitative approach through in-depth interviews with a number of enterprises and firms focused in the industry of plastic, we have got this finding about the conducting of the international strategy in the Egyptian SMEs in this specific field.

Concerning the contribution of the advantage to have a successful conquest in the global market and their criteria for choosing the target countries, these firms export to countries that are similar to Egypt in their economic situation and market conditions, such as: Libya, Sudan, Jordan, Greece, and Cyprus. They target the regions that share an economic situation as similar as possible to Egypt, such as the MENA region and markets that are open with a good potential which are mainly the Gulf countries which do not have many producers of plastics. The firm's objectives are markets with fewer competitors and with a potential that is matching with the prices and qualities they offer. So they benefit from the same market domination they maintain in Egypt. They managed to maintain a successful sustainability even during the financial crisis on 2008-2009 and since the Arab Spring has started, by adapting to the new circumstances and implementing new politics in order to be relevant to the market changes.

Meanwhile, due to the increasing inflation rate in Egypt and the revolutionary dollar rate nowadays, the foreign transactions are becoming very limited.

The analysis of the interviews with these SMEs was more or less decrypting some major concerns towards the following:

-The insurance of transferring the competitive advantage to the target countries: it starts from having a clear and definitive agreement which states the regulations they need to clarify or brand identity and guarantee the highest standards of protection to their products and pick wisely their logistics centers to ensure the delivery of products in their best shape.

-Setting an adapted international strategy: they had a sort of stability while implementing the pure model of strategy before January 2011, but then they stopped exporting to many Arab countries due to the lack of security caused by the political changes and became more focused on the national market and foreign countries outside the MENA region. They also started to reduce the capacity of production, their mass production turned into work by command in order to reduce the production costs and have more control on the risk factors. Briefly, they observe the market changes and adapt accordingly.

-Establishing an effective coordination and communication with international partners: they always seek different methods of communication as it helps creating a smoother process and increasing the efficiency; they provide exchanges and internships especially with the nearby countries and most of them organize schedules of regular visits for their main machine provider ( usually in China). They also try to join as much international exhibitions as possible to benefit from the diversity and be able to reserve a place on the global platform.

-The influence of international economic and political instability on international activity: concerning types of partnerships with the international partners in the past three years, these SMEs experienced a very unstable political situation affected by the economy and security of the country, but most of the partners in the MENA region had a kind of understanding between both sides. Most of the interviewed SMEs tried to overcome any difficulties happening, they took actions in order to provide them some sort of security and implemented new politics for the payments and cancellations, raised the agreements' conditions regarding delays and risks in general to reflect a potential of commitment and efficiency. 
There's a sort of recession growing more and more due to the economic and political instability which leads to a decreasing rate of demand so the incomes started also to decrease especially with the lack of security.

-The way this situation affects the international strategy and/or its implementation: SMEs were forced to limit expansions and focus on the markets they already penetrated as the circumstances keep changing and becoming more difficult. They also stopped the mass production and began working by command to reduce risks.

In fact, according to this survey, we noticed that:

-As our opinion and according to most of researchers, to drive a successful international strategy, the important concern is to ensure the coherence between the choices of countries, the rhythm of development, the degree of adaptation of the value proposition, the capabilities of transferring the key competencies, and the entry modes. The formulated strategies overall or by activity field redefining or not the geographical zone of the company, they generally involve important organizational changes. From this point of view, the transition from decisions to actions comes up against the defensive organizational routines. That is what we call, the pure model.

-Behind this pure model -more or less- adapted by firms, many globalization models exist in practice. Schematically, it is possible to distinguish various globalization models capable to face the common challenges of instability: Globalization by projection, Globalization by a geocentric approach, or mixing both of them.

\subsection{Strategy of Globalization by Projection}

For Michael Porter, the precondition of becoming the global leader by a global strategy is to focus on a global platform. For example, the most important ten markets of the chocolate industry in the world represent $71 \%$ of the global market.

The "globalized" advantage is invented and developed from a global platform that is the most advanced country in a given activity. This advance is related to the association of a group of factors called the "Diamond of Porter". This diamond consists of these elements:

- A purchasers' market particularly demanding, sophisticated, and large enough;

- An access to resources, knowledge and production factors that allow the development of distinctive and strong competences;

- A structure of stimulating rivalry;

- And a connected tissue of related industries or performing support.

The companies that are developed and placed in this type of environment have a good chance to reach success and globalization. However, they should apply a rigorous approach and aggressive politics investment in the key countries. This process includes the following steps:

- Identifying the integrated markets on a global level, to be established commercially and transfer the competitive advantage by a standard formula;

- Localizing the chain value activities in the global space so that the efficiency of the system group increases (concept of additional advantage that reinforces the domestic initial one);

-Understanding and implementing the organizational processes to integrate and coordinate the chain links in order to ensure the efficient functioning of the system and increase the competitive advantage.

Identification and classification of the targeted markets:

In fact, markets are classified according to the size, rate of growth, and permeability degree. This classification allows identifying the strategic issues in six categories of countries and the type of actions to take. - Basic country: at the beginning the basic country is the country of origin, it means the global platform. In case of a mature multinational company, the basic countries are the most important markets in terms of size and resources, in which the company maintain a leading position. In the chocolate bars activity, the basic countries of Mars are the United States and England. The basic countries are the territories that generate the biggest part of the financial ability for growth and in which the products and communication politics are developed. The main competencies and resources for developing new abilities are localized in the basic country or countries. 
- Targeted countries: they're the important countries in terms of market size for the group of strategic subsegments. In these countries, the growth rate is sustained and the leader is not affirmed yet. For Mars, Russia and Ukraine form the "targeted countries". In these countries, it's about concentrating the appropriate resources to modify the situation for the company's good, by implementing production units inserted in the industrial system of the company on the global scale. The objective is to make these countries turn into basic countries; the horizon of return on investment is in the order of five to ten years.

- Priority countries: they're the most important countries for one or many sub-segments that are open to the outside and with a high growth. Mexico and Turkey are priority countries for Mars. In these countries, the objective is to be among the first two competitors in one or many sub-segments, with a horizon of return on investment of five years. These countries can be a production bases for certain components.

-Leading countries: they're the most important in terms of market size. They form the bases for the big competitors. The competitive situation is fixed. Germany is considered as a leading country by Nike because it's Adidas' basic county. In these countries, it's about targeting small battlements, with the aim of interfering and monitoring competition. In this type of markets, the ideal is to invest enough to establish a tool of deterrence and strategic insurance in order to engage -if possible- reprisal actions against the main global competitor, in case this one will become a threat in the basic and targeted countries.

- Recess countries: they're the countries with important potential markets but closed. They are not integrated in the global market then. They remain on the periphery of the global industry, but form some recesses because the market size is important. In these countries, a potential competitor can hide while profiting from a protected situation. In this case, limiting actions could be taken, for example, firms can sign license contracts with local competitors suspected to bother the accumulation of resources of the potential client. If they anticipate a market opening with more or less short maturity, it's conceivable to take an option by means of a minority joint venture. China and India could be considered as recess countries for Nike. - Country with opportunity: they're the countries that don't represent an important market or which have been closed for so long. They could invest the minimum there to take the opportunities from a side and to export products via these basic countries.

The classification by strategic issues and by action types is an essential element of the global strategy. Furthermore, the international competitive game requires a good cash management. The occupied space must be increased continuously by using the available way to the maximum.

\subsection{The Integration and Coordination of Activities}

In this model of globalization by projection, the physical, strategic and organizational integration are relatively simple: the decisions and upstream chain value activities are centralized: the downstream operations are assigned to the dispersed units. These units execute the operations according to the directives of the center. The commercial units of the countries are considered as centers of revenues. Their actions are organized and orchestrated by a global marketing by production line. In reality, this model is hard to be applied because it is rare that a firm can build its chain value in the global space as if they are assembling pieces of "lego" Generally, the manufacturing units or the other system links are historically localized in some countries. Their localization is the result of other strategic decisions. For all of these reasons, it's hard to build a chain value with the problem of optimizing the efficiency and to solve the problem of the physical flows integration by the sequential organization.

\subsection{Strategy of Globalization by a Geocentric Approach}

The globalization model by projection finds its limits very fast when the competition in the key countries is structured by actors that adopt different approaches and develop continental or local value propositions. In the chocolate industry, in the early ninety years, the world agreed that the overall segment of chocolate bars would develop irresistibly at the expense of tablets and chocolates confectionary. In fact, they were characterized by strong local specifications. It was expected that the development of chocolate bars would standardize the tastes and reduce the consuming of local products. Actually, the traditional segments of chocolate perfectly resisted to the rise of Mars and Nestlé-Rowntree bars. The expansion of Mars' global products structured in six international mega brands is stopped in Western Europe. In addition, "the European alternative to the heavy bars of Mars" means light and crispy bars embodying more Mediterranean flavor are developed by Ferrero and Jacobs Suchard, especially Ferrero with his European bars that has attacked Mars and Nestlé on their own ground.

This alternative model of globalization is getting developed then, specifically since the mid-eighties. This geocentric approach model consist on a basic formula, Instead of transposing the strategic "earning" concept 
of the domestic country to the entire world, it tends to identify the common denominator between the key markets. This approach differs from the previous one by the way of organizing the chain value and defining (or redefining) the value proposition. The chain value activities are always tightly coordinated and integrated on the international level. In contrast, this integration is not orchestrated by a unique center but by multiple strategic centers. The different countries play the leader role for the different sub-groups of activities. In addition, the chain value activities are dispersed not just according to a vertical logic of specialization, but also according to a horizontal logic of specialization ${ }^{1}$.

\section{CONCLUSION}

Considering the actual economic and political situation in Egypt, the geocentric model of globalization of international strategy is hard to be implemented. The flaws are many. The system is vulnerable to disturbances localized to a particular place here and there. The mode of organizing in projects and horizontal teams can destabilize the whole. The mechanisms of control to be implemented to ensure the coherence of the whole are complicated. Meanwhile, this model is very pertinent for the activities of a global character and with a fast technological evolution.

There's no unique model of internationalization. There's also no determinism driving the industries to the globalization. In contrast, the different and sometimes opposed models coexist. The international expansion process of a firm follows neither a linear logic nor some pre-determined steps (while the dominating theories of the internationalization process are based on the concept of an evolutionary approach by pre-determined steps). That is why the international strategies are marked by the breaks and changes of models. In order to drive an international expansion, the most important is to ensure the coherence between the choices of countries, the rhythm of development, the degree of adaptation of the value proposition, the capabilities of transferring the key competences and the entry modes.

The formulated strategies overall or by activity field redefining or not the geographical zone of the company, generally involve important organizational changes.

In this phase of instability, the global market conquest by the systematical usage of a unique strategic model must focuses on a developed competitive advantage in the country of origin. That is why globalization by projection involves the systematic transfer of this advantage to the countries that constitute the essential of the global market. However, in most sectors, the countries of the Triad represent more than $70 \%$ of the global market and it's pertinent to focus on the biggest ten or twenty representing from 70 to $80 \%$ of the global demand. This strategy supposes that the developed model in the country of origin is applicable in a big number of key countries. The first condition for the success of a global strategy then is the high permeability of the markets to the value proposition of the applicant firm at the globalization.

The perfect situation is the balance between resources and commitments, when the resources being less than liabilities become an upward trend, which is subject to SMEs in Egypt now.

Bringing foreign currencies as well as increasing foreign direct investment rates will positively impact export. Egypt by virtue of its place is an industrial zone of the first class and can bring in and export of raw materials all around the world and the region by establishing technology intensive industries, labor services, projects for logistics ships and maritime transport as well as the activity of storage and transit. We have to note that the high population density in the Egyptian market makes it an attractive market for investment in several sectors including tourism, medical services, plastic, ceramic \& porcelain industries, petrochemical, food, and retail sector.

New strategies of implementation and new entry mode are required to prepare investment hub in line with the development process in the region.

In general, the economic and social progress throughout the world depends in large measure on a steady expansion in international trade. The extensive development of equitable and mutually advantageous international strategies adapted by firms creates a good basis for the establishment of neighborly relations between countries, helps to strengthen peace and an atmosphere of mutual confidence and understanding among nations, and promotes higher living standards and more rapid economic progress in all countries of the world (UNCTAD, 1964).

\footnotetext{
1 The horizontal specialization describes the repartition of activities between the geographic units according to the logic of specific competences related to the same step of the chain value. The process of integration is then parallel or synchronized.
} 


\section{REFERENCES}

Burdon S., Chelliah J., Bhalla A. (2009). Structuring enduring strategic alliances: the case of Shell Australia and Transfield Services, Journal of Business Strategy, 30(4), 42-51.

Byrne S., Popoff L. (2008). International Joint Ventures Handbook, Baker \& McKenzie.

Campbell E., Reuer J.J. (2001), International Alliance Negotiations: Legal Issues for General Managers, Indiana University Kelley School of Business, Business Horizons Copyright.

Carnegy H. 1995. Struggle to save the soul of IKEA, Financial Times (27 March 1995).

Elmuti D., Kathawala Y. (2001). An overview of strategic alliances, Management Decision 39/3 205-217, MCB University Press.

Geringer J.M., Hebert L. (1989). Control and Performance of International Joint Ventures, Journal of International Business Studies, 20(2), 235-254.

Grant R.M., Baden - Fuller Ch. (2004,1 January), A Knowledge Accessing Theory of Strategic Alliances, Journal of Management Studies 41: 0022-2380.

Jagersma P.K. (2005), Cross - border alliances: advice from the executive suite, Journal of Business Strategy,2(1), 41-50.

Janoff, B. (1991) 'Surviving recession', Progressive Grocer, 80, 5, 16-24.

Kale P, Singh H. (2009), Managing Strategic Alliances: What Do We Know Now, and Where Do We Go From Here? Perspectives, Academy of Management.

Killing J.P. (1982, May - June). How to Make a Global Joint Venture Work, Harvard Business Review, No. 82310.

Kling K., Gofeman I. (2003). Ikea CEO Anders Dahlving on international growth and Ikea's unique corporate culture and brand identity, Academy of Management Executive.

Meyer, A. D. (1982) 'Adapting to Environmental Jolts', Administrative Science Quarterly, 27, 4, 515-37.

Slatter, S. (1984) Corporate Recovery, Penguin, Harmondsworth

Slywotzky A., Hoban Ch. (2007), Stop competing yourself to death: strategic collaboration among rivals, Journal of Business Strategy, 28(3), 45-55.

Retrieved from http://www.emeraldinsight.com/journals.htm?articleid=1603609\&show=html

Terpstra V., Sarathy R. (2001). International Marketing, 8th edn., Chicago II, Dryden Press.

Whittington, R. (1989) Corporate Strategies in Recession and Recovery: Social Structure and Strategic Choice, Unwin Hyman, London.

Yip G. (2002). Total Global Strategy, London Prentice-Hall.

Zou G., Cavusgil S.T. (2002). The GMS: a broad conceptualization of global marketing strategy and its effect on firm performance, Journal of Marketing, 66, pp. 40-57. 